\title{
Александрия в ранневизантийское время: общественные волнения и конфликты
}

\author{
М.А. Руднева \\ Белгородский государственный национальный исследовательский университет, \\ РФ, 308015, г. Белгород, ул. Победы, 85 \\ E-mail: rudneva@bsu.edu.ru
}

\begin{abstract}
Аннотация. Статья посвящена изучению роли общественных волнений и конфликтов в истории Александрии в ранневизантийское время. Город являлся одним из ключевых центров региона, играл важную роль в политической, социально-экономической и культурной жизни империи. Нестабильность внутреннего положения была характерна и в предшествующие столетия существования города, однако в ранневизантийское время волнения и конфликты стали происходить чаще. Это было связано как с внутренними процессами - неравномерностью социально-экономического развития, борьбой за гегемонию в городе между этноконфессиональными группами иудеев, язычников и христиан, противоборством в политике, так и с внешними факторами - политической нестабильностью в империи, религиозными разногласиями, внешними угрозами. Таким образом, можно сделать вывод, что волнения и конфликты в Александрии являются ярким проявлением противоречий ранневизантийского времени.
\end{abstract}

Ключевые слова: Поздняя античность, ранняя Византия, Александрия Египетская, волнения, конфликты.

Для цитирования: Руднева М.А. 2020. Александрия в ранневизантийское время: общественные волнения и конфликты. Via in tempore. История. Политология, 47 (3): 518-524. DOI 10.18413/2687-0967-2020-47-3-518-524.

\section{Alexandria city in the early byzantine time: social unrest and conflicts}

\author{
Maria A. Rudneva \\ Belgorod National Research University, \\ 85, Pobeda St., Belgorod, 308015, Russia \\ E-mail: rudneva@bsu.edu.ru
}

\begin{abstract}
The article is devoted to studying the role of unrest and conflicts in the history of Alexandria in the Early Byzantine time. The city was one of the key centers of the region, played an important role in the political, social, economic and cultural life of the empire. The instability of the internal situation was characteristic in the previous centuries of the city's existence, however, in the Early Byzantine time unrest and conflict began to occur more often. This was due both to internal development processes - uneven social and economic development, the struggle for hegemony in the city between ethnic and religious groups of Jews, pagans and Christians, confrontation in politics, and external factors - political instability in the empire, religious differences, external threats. Thus, we can conclude that the unrest and conflicts in Alexandria are a vivid manifestation of the contradictions in the Early Byzantine time. Episodes of aggravation of the situation in the city allow us to study the whole complexes of contradictions that existed both within Alexandria and in the process of empire development. The study of the dynamics of changes in the city is important for understanding the features of historical development in the conditions of transformational processes.
\end{abstract}

Keywords: Late Antiquity, Early Byzantium, Alexandria, Egypt, unrest, conflict. 
For citation: Rudneva M.A. 2020. Alexandria city in the early Byzantine time: social unrest and conflicts. Via in tempore. History and political science, 47 (3): 518-524 (in Russian). DOI 10.18413/2687-0967-2020-47-3-518-524.

Александрия Египетская, построенная Александром Македонским, быстро утвердилась в качестве одного из ключевых центров региона. Являясь опорой для власти Птолемеев, а потом и римлян в Египте, город был важным административным центром, достиг большой численности населения, активно развивался в социально-экономическом плане, обрёл славу мощнейшего интеллектуального центра. В ранневизантийское время Восточная Римская империя переживала процесс трансформации, все стороны которого проявились в истории Александрии. Эпизоды обострения обстановки в городе позволяют изучить целые комплексы противоречий, существовавших как внутри Александрии, так и в самом процессе развития империи. Исследование динамики изменения города имеет важное значение для понимания особенностей исторического развития в условиях трансформационных процессов. Данные вопросы получили значительное внимание в зарубежной историографии. Например, монография Кристофера Хааса во-многом концентрируется именно вокруг конкурентного характера социальной динамики развития религиозных и этнических сообществ города [Haas, 1997]. Борьба различных групп за социальное господство и культурную гегемонию часто приводила к значительным разрушениям и выливалась в насилие, нестабильная ситуация усугублялась имперским вмешательством. Однако автор монографии не считает такое положение нормальным, отмечая, что в повседневной жизни александрийские этноконфессиональные группы находились в тесном сотрудничестве. Особенно ярко эта закономерность проявлялась в социально-экономических отношениях [Haas, 1997].

В римское время власти неоднократно сталкивались с волнениями в городе и приводили александрийцев к повиновению насильственными методами. Примером могут служить еврейские восстания в Александрии - Первая Иудейская война (66 г.), Вторая Иудейская война (115-117 гг.), восстание буколов (пастухов) в Нижнем Египте (172 г.) и др. Кроме того, волнения были связаны с нестабильностью в империи и появлением узурпаторов, например, восстанием Гая Авидия Кассия (175 г.), восстанием Песценния Нигера (193 г.). Город был охвачен военными действиями в связи с указом императора Каракаллы в 216 г. Позднее он был захвачен царицей Пальмиры Зенобией, а также осаждён в процессе возвращения под власть Римской империи в 272 г.

Анализ ранневизантийских источников обнаруживает, что нестабильность внутренней ситуации в городе была связана с важнейшей экономической ролью города, амбициями городских элит в политической и культурной жизни империи, сложным этноконфессиональным составом населения. В ранневизантийское время управление неспокойным городом требовало значительных усилий. Анонимный автор сочинения «Ехроsitio totius mundi et gentium», созданного в IV веке, утверждал, что «этот город навязывает свою волю правителям» (Ехроsitio, 37, 1-5).

Характерной чертой ранневизантийских общественных конфликтов и восстаний в городе можно считать их религиозный характер, который они приобрели в связи с христианизацией империи. Реакция со стороны власти на распространение христианства повлекла за собой гонения на последователей данной религии. Особое место в источниках уделяется гонениям во времена императора Диоклетиана, когда «его послания дошли до Александрии и Египта; и он навел суд на христиан, и разрушил церкви Божии, и убил многих людей мечом; и те, которые уверовали во Христа, бежали в пустыню, в логова и пещеры» (History of the Patriarchs, 1.6 Evetts, p. 383). Диоклетиан установил стражу и дозорных в каждом месте города. Иоанн Никиусский пишет, что события в Александрии стали причиной убийства «всех епископов Египта» (John. Nik., 77.12 Charles). Эти события в описании Иоанна Никиусского приобретают апокалиптические черты (John. Nik., 77.7; 77.12). Особо отмечено жестокое пре- 
следование христиан и мученическая гибель патриарха Петра. Его арест и решение о его казни спровоцировали народные волнения (History of the Patriarchs, 1.6 Evetts, p. 383). Александрию затронули и гонения императора Галерия (John. Nik., 77.25). Постепенно христианство набирало силу, но его распространение не было однородным и стабильным. Волнения и конфликты в Александрии были связаны в это время с отсутствием единства в церкви. Целый ряд инцидентов насильственного характера в Александрии был связан с борьбой против арианства. После осуждения учения Ария в качестве ереси на Первом Вселенском Соборе (325 г.) значительную деятельность по противодействию арианству проводил архиепископ Александр Александрийский (архиеп. 312/313-328 гг.) (Soc., HE, I, 5-8; Ruf., HE, I, 1-2). В то же время, деятельность архиепископа Александра оценивается неоднозначно. Так, церковный историк Сократ Схоластик пишет о том, что послание Александра против Ария лишь усугубило ситуацию, и «зло ещё более увеличилось» (Soc., HE, I, 6).

Политику своего предшественника на престоле Александрийской церкви продолжил Афанасий Александрийский (295/297-373 гг.) [Саврей, 2011]. Ещё в молодом возрасте Афанасию удалось присутствовать на Первом Вселенском соборе, где он выступал на стороне противников Ария (Soc., HE, I, 8; Ruf., HE, I, 5). Утверждение Афанасия в качестве архиепископа, последовавшее после смерти Александра (328 г.) (Soc., HE, II, 17), сопровождалось волнениями, связанным с мелитианами (Sozom. HE. II. 21, 22). Мелитиане продолжали деятельность по поддержке арианства. Эту позицию они заняли ещё во время служения Александра [Сидоров, 2013]. Поэтому уже в начале своего архиепископства Афанасий столкнулся с интригами, которые сопровождали его на протяжении последующего времени.

Не вдаваясь в подробное описание весьма насыщенного пути Афанасия, заметим, что он неоднократно изгонялся из Александрии и возвращался вновь, подвергался преследованиям. Эти события сопровождались волнениями в городе. В результате одного из таких волнений в 361 г. был убит арианский епископ Георгий Каппадокийский (Soc., HE, III, 2; Sozom., HE, V, 7). Церковные историки, стремясь смягчить этот инцидент, отмечают, что александрийцы немало претерпели от Георгия (Sozom., HE, IV, 10), что привело к росту ненависти в его сторону со стороны общества (Sozom., HE, IV, 30). При этом вина за убийство Георгия возлагается Созоменом на представителей языческой черни. Этот инцидент получил острую реакцию имперских властей (Soc., HE. III. 3).

Императоры на протяжении всего времени арианских споров стремились регулировать положение в городе (Athan. Apol. contra Ar., 51, 87; Hist. Ar., 48 col. 752c; 51 col. 756b; Julian. Ep., 24 (398); Soc., HE, III, 13; IV, 13). При этом позиция власти не была однозначной. Императоры поддерживали ту или иную сторону в соответствии со своими интересами. Например, известен случай, когда император Константин первоначально поддерживал Афанасия Александрийского, однако, когда последнего обвинили в угрозах прервать поставки зерна из Египта в Константинополь, резко изменил свои взгляды (Soc., HE, I, 35; Athan. Apol. contra Ar., 87 col. 405a).

После смерти Афанасия в 373 г. в городе произошли волнения, связанные с народным недовольством новым архиепископом Александрии, сторонником арианства - Лукием (Sozom., HE, VI, 19). Он был окончательно изгнан в 379 г. (Soc., HE, IV, 37). Созомен обозначает, что в изгнании Лукия и возведении на престол Петра II (архиеп. 373-380 гг.) основную роль сыграло население Александрии (Sozom., HE, VI, 39). Также противником ариан был ученик и последователь Афанасия Тимофей I (архиеп. 380-385 гг.).

Александрию затронули не только процессы, связанные с гонениями на христиан и отсутствием единства в уже утвердившемся христианстве. Значительные волнения были связаны с утверждением христианства в качестве доминирующей силы в городе. Усиление христианской церковной иерархии постепенно приводило к вытеснению её оппонентов на периферию, влекло за собой обострение ситуации.

Решения Второго Вселенского собора (381 г.) способствовали утверждению христианства в качестве государственной религии. Эти события привели к усилению антиязыческой 
политики. В Александрии во время предстоятельства Феофила Александрийского (архиеп. 385-412 гг.) в 391 или 392 гг. были разрушены храм Диониса, театр, пострадала значительная часть античных статуй, но главное - был разрушен грандиозный языческий храм Серапеум ${ }^{57}$. Этот храм был посвящен главному божественному покровителю города - синкретическому богу Серапису. Разрушение Серапеума сопровождалось борьбой язычников и христиан, повлекшей за собой жертвы. Событие получило широкий отклик в источниках (Eunap., Vit. soph., VI, 2; Soc., HE, V, 16; Sozom., HE, VII, 15; Ruph., HE, XI, 23, et al.). При этом, в зависимости от позиции автора, его конфессиональной принадлежности и иных причин, сообщения разнятся как в плане описания события, так и в оценке действий противоборствующих сторон. Тем не менее, авторы источников упоминают участие александрийцев в столкновениях, описывая жестокость как христиан, так и язычников (Sozom., HE, VII, 15). При этом особо выделяется оценка Евнапия, который, в отличие от христианских авторов, описывает разрушение Серапеума не как торжество христианства над язычеством, а как гибель векового античного наследия. Христиан же он выставляет в негативном свете, сообщая, что они не гнушались воровством (Eunap., Vit. soph., VI, 2). Это событие являет собой кульминационный момент в ослаблении язычества в ранневизантийском Египте [Haas, 1997]. Языческий культ, не представлявший единства и выкристаллизовавший свою самоидентичность лишь в столкновении с набиравшим силу христианством, потерпел поражение, но не исчез, так как языческие практики продолжали существовать на протяжении последующих столетий.

Значительной областью развития языческого сообщества оставалась сфера образования, которая позволяла широко транслировать классическое наследие, без акцента на религиозную составляющую [Watts, 2006].

Следующий «виток» утверждения христианства в Александрии произошёл в предстоятельство Кирилла Александрийского (архиеп. 412-444 гг.). Автор многочисленных трудов, он получил известность в качестве одного из наиболее успешных борцов за единство церкви, являясь противником несторианства [Сидоров, 2000]. Его восшествие на престол Александрийской церкви сопровождалось интригами и противоборством со стороны сторонников второго претендента - Тимофея [Лященко, 1913]. Сократом Схоластиком упоминается «народное смятение», относящееся к этому времени (Soc., HE, VII, 7). Ранний этап предстоятельства Кирилла был одним из наиболее напряженных в ранневизантийской истории Александрии. На это время приходятся такие события, как закрытие новацианских церквей (Soc., HE, VII, 7) и изгнание иудеев (Soc., HE, VII, 13; John. Nik., 84. 87-103). Но наибольший резонанс вызвало убийство языческого философа Гипатии Александрийской в 415 г. (Soc., HE, VII, 13-15; John. Nik., 84.45). Роль Кирилла в этом инциденте, его противостояние с префектом Орестом, а также действия монахов, выступивших в этом конфликте на стороне архиепископа (Soc., HE, VII, 13-15), продолжают интересовать исследователей и в настоящее время ${ }^{58}$.

Период наибольшего усиления христианства в Александрии совпадает с большим количеством общественных конфликтов ввиду того, что отдельные группы вытесняются с ранее занятых позиций в социальной иерархии.

Победа и последующее доминирование христианства не устранили существовавших противоречий, которые нарушали единство церкви. Александрия была одним из центров распространения монофизитства, осужденного в 451 г. на Халкидонском соборе. По мнению исследователей, к последствиям решений собора можно отнести более отчетливое разделение Александрийской церкви на монофизитскую (коптскую) и греко-византийскую [Саврей, 2011]. Противостояние приверженцев этих направлений определило череду конфликтов в Александрии, не прекращавшихся на протяжении столетий.

${ }^{57}$ Вопрос определения точной даты разрушения Серапеума является дискуссионным [Hahn, 2008; Vedeshkin, 2014].

58 Ввиду небольшой информативности источников, многие вопросы данной проблемы носят дискуссионный характер [Ведешкин, 2014; Lacombrade, 1994; Dzielska, 1996; Haas, 1997; Ronchey, 2001; Watts, 2017, et al.]. 
Вскоре после Собора в Александрии был низложен монофизитский патриарх Диоскор и возведён халкидонит Протерий. Однако уже в 457 г. умер император Маркиан, покровительствовавший халкидонитам. В Александрии произошли волнения, в ходе которых Протерий был убит (Zach., IV , 2), а на его место был возведен Тимофей II Элур (Zach., $\mathrm{IV}, 1)$. Захария Митиленский видит причины убийства Протерия в его недостойном поведении. Евагрий Схоластик обвиняет в убийстве разбушевавшуюся александрийскую чернь (Evagr., II, 8). Феофан Исповедник обвиняет Тимофея, который подкупом и силой овладел Александрийским престолом (Theoph., Chron., 5950) и подослал к Протерию убийц. Евтихий наряду с лаконичным изложением событий (Eutychius, Annales, 101-103 (Patrologia Graeca, 111, col. 1055)) обозначил место сожжения тела Протерия - ипподром (Eutychius, Annales, 108 (Patrologia Graeca, 111, col. 1056)). На оценку авторов повлияло их отношение к Халкидонскому собору [Кириллов, 2016], тем не менее роль взбунтовавшегося населения в данных событиях очевидна [Кулаковский, 2003]. Впоследствии беспорядками в Александрии сопровождалось изгнание Тимофея II Элура (John. Nik., 88. 23-25).

Ещё одним крупным событием стал случай нападения на языческие святилища в Менуфисе, последовавший за избиением студента по имени Паралий. Инцидент произошел в Александрии в конце V века (вероятно, весной 486 г.) [Barnes, 2012]. Эта история подробно описана в «Житии Севера» Захарии Митиленского и «Жизни Исидора» Дамаския. Эпизод получил подробный анализ в монографии Эдварда Уоттса [Watts, 2010]. Схоластическое наказание приобрело религиозный оттенок и в короткие сроки разрослось во внутригородской конфликт, потребовавший вмешательства имперских властей. В результате конфликта было подорвано единство неоплатонической школы Александрии [Watts, 2010].

Кроме того, угроза столкновений в городе существовала в правление императора Юстиниана. Согласно сообщению Иоанна Никиусского, в Александрию были отправлены войска из Африки. Открытого столкновения удалось избежать при активном участии патриарха Тимофея IV, которому покровительствовала императрица Феодора (John. Nik., 90. 88-90).

После смерти Тимофея в 537 г. возникли волнения на почве разногласий между сторонниками Феодосия и Гайны (Гайана), в связи с чем образовались партии феодосийцев и ганиян. Этот и другие эпизоды являются продолжением противостояния монофизитов и халкидонитов, а также внутренних распрей среди антихалкидонитов.

В VII веке Александрия оказалась в центре восстания Ираклия против императора Фоки. В 610 г. Александрия была захвачена войсками под командованием Никиты и стала надежной базой для восставших, что предопределило их победу. После небольшого периода затишья город, как и вся империя, столкнулся с военной угрозой со стороны Сасанидского Ирана. Это время связано с противостоянием захватчикам (616/618-619 гг.) и периодом персидского господства в Александрии (619-629 гг.). Возвращение города в состав Восточной христианской империи было недолгим, так как в 642 г. ослабленная империя была вынуждена уступить город арабам.

Таким образом, ранневизантийская история Александрии связана с процессом трансформации классических форм и преобразованиями, связанными с христианизацией. Эти процессы обостряли проблемы политического, социально-экономического, межконфессионального характера. В результате конфликтов менялся баланс сил, который зависел в том числе от позиции имперских властей. Противоречия, существовавшие в Александрии, не получили разрешения в ранневизантийское время, они потеряли свой масштаб и остроту лишь в ходе дальнейшего существования города уже в рамках арабо-исламской цивилизации.

\section{Список литературы}

1. Ващева И.Ю. 2013. Феномен «Церковных историй» в эпоху Поздней античности. Диссертация на соискание ученой степени доктора исторических наук. Нижний Новгород, 789.

2. Ведешкин М.А. 2014. Языческая оппозиция христианизации Римской империи: IV-VI вв. Диссертация на соискание ученой степени кандидата исторических наук. Москва, 316. 
3. Кириллов В.М. 2016. Захария Митиленский о событиях 457 г. в Александрии. Классическая и византийская традиция. 2016. Материалы Х научной конференции. Белгород, 101-105.

4. Кулаковский Ю.А. 2003. История Византии. В 3-х томах. 3-е изд. Том 1. 395-518 годы. Санкт-Петербург, Алетейя, 496.

5. Лященко Т., свящ. 1913. Св. Кирилл, архиепископ Александрийский. Его жизнь и деятельность. Киев, 547.

6. Сидоров А.И. 2000. Святитель Кирилл Александрийский. Его жизнь, церковное служение и творения. Творения святителя Кирилла епископа Александрийского. Кн. 1. Москва, Паломник, 735.

7. Сидоров А.И. 2013. Святоотеческое наследие и церковные древности. Том 3: Александрия и Антиохия в истории церковной письменности и богословия. Москва, Сибирская Благозвонница, 732.

8. Barnes T.D. 2012. Review of Riot in Alexandria: Tradition and Group Dynamics in Late Antique Pagan and Christian Communities. The Transformation of the Classical Heritage, 46. The Catholic Historical Review. 98: 86-87.

9. Dzielska M. 1996. Hypatia of Alexandria. Cambridge, MA, London, 176.

10. Haas C. 1997. Alexandria in Late Antiquity: topography and social conflict. Baltimore; London, Johns Hopkins University press, 494.

11. Haas C. 2010. Alexandria Lost? Cleopatra and the End of the Hellenistic World. Franklin Institute and the University of Pennsylvania Museum of Archaeology and Anthropology. Philadelphia. URL: https://villanova.academia.edu/ChristopherHaas (дата обращения: 01.04.2020) (access date: 18.04.2020).

12. Hahn J. 2008. The Conversion of the Cult Statues. The Destruction of the Serapeion 392 A. D. From Temple to Church. Religions in the Graeco-Roman World, 161. Leiden, 335-366.

13. Kristensen T. 2009. Religious Conflict in Late Antique Alexandria: Christian Responses to «Pagan» Statues in the Fourth and Fifth Centuries CE. Alexandria. A Cultural and Religious Melting Pot. G. Hinge and J.A. Krasilnikoff (eds.). Aarhus, Aarhus University Press, 158-173.

14. Lacombrade C. 1994. Hypatia. Real lexikon für Antike und Christentum [Hypatia. Real Encyclopedia for Antiquity and Christianity. Volume 16]. Band 16. Stuttgart, 956-967 (in German).

15. Łukaszewicz A. 2013. Lecture Halls at Kom el-Dikka in Alexandria. Divine men and women in the history and society of late Hellenism. Cracow, 101-112.

16. McDonald W. 2009. Alexandria in Late Antiquity: Topography and Social Conflict. By Christopher Haas. Baltimore: The Johns Hopkins University Press, 1997. 494 p. Church History: Studies in Christianity and Culture, 67(1). Cambridge: Cambridge University Press: 116-117.

16. McKenzie J. 2007. The Architecture of Alexandria and Egypt 300 B. C. to A. D. 700 . New Haven; London, 460.

17. McKenzie J.S., Gibson S., Reyes A.T. 2004. Reconstructing the Serapeum in Alexandria from the Archaeological Evidence. The Journal of Roman Studies. Vol. 94: 73-121.

18. Ronchey S. 2001. Hypatia the Intellectual. Au. Fraschetti (eds.). Roman Women. Chicago; London, 160-189, 227-235.

19. Watts E.J. 2006. City and School in Late Antique Athens and Alexandria. The Transformation of the Classical Heritage 41. Berkeley; Los Angeles, University of California Press, 302.

20. Watts E.J. 2010. Riot in Alexandria: Tradition and Group Dynamics in Late Antique Pagan and Christian Communities. Berkeley, University of California Press, 290.

21. Watts E.J. 2017. Hypatia: The Life and Legend of an Ancient Philosopher. New York, Oxford University Press, 224.

\section{References}

1. Vashheva I.Ju. 2013. Fenomen «Cerkovnyh istorij»v jepohu Pozdnej Antichnosti [The phenomenon of «Church stories» in the era of Late Antiquity]. Dissertacija na soiskanie uchenoj stepeni doktora istoricheskih nauk. Nizhnij Novgorod, 789 (in Russian).

2. Vedeshkin M.A. 2014. Jazycheskaja oppozicija hristianizacii Rimskoj imperii: IV-VI vv. [The pagan opposition of the Christianization of the Roman Empire: IV-VI centuries A. D.] Dissertacija na soiskanie uchenoj stepeni kandidata istoricheskih nauk. Moskva, 316 (in Russian).

3. Kirillov V.M. 2016. Zaharija Mitilenskij o sobytijah 457 g. v Aleksandrii [Zachariah of Mitilena about the events of 457 in Alexandria]. Klassicheskaja i vizantijskaja tradicija. 2016. Materialy $\mathrm{X}$ nauchnoj konferencii [Classical and Byzantine tradition. 2016. Materials of the X Scientific Conference]. Belgorod, 101-105 (in Russian). 
4. Kulakovskij Ju.A. 2003. Istorija Vizantii [History of Byzantium]. V 3-h tomah. 3-e izd. Tom 1. 395-518 gody. Sankt-Peterburg, Aletejja, 496 (in Russian).

5. Ljashhenko T., svjashh. 1913. Sv. Kirill, arhiepiskop Aleksandrijskij. Ego zhizn' i dejatel'nost' [St. Cyril, Archbishop of Alexandria. His life and work]. Kiev, 547 (in Russian).

6. Sidorov A.I. 2000. Svjatitel' Kirill Aleksandrijskij. Ego zhizn', cerkovnoe sluzhenie i tvorenija [Saint Cyril of Alexandria. His life, church ministry, and creations]. Tvorenija svjatitelja Kirilla episkopa Aleksandrijskogo [Creations of St. Cyril Bishop of Alexandria]. Kn. 1. Moskva, Palomnik, 735 (in Russian).

7. Sidorov A.I. 2013. Svjatootecheskoe nasledie i cerkovnye drevnosti [Patristic heritage and church antiquities]. Tom 3: Aleksandrija i Antiohija $\mathrm{v}$ istorii cerkovnoj pis'mennosti i bogoslovija [Alexandria and Antioch in the History of Church Writing and Theology]. Moskva, Sibirskaja Blagozvonnica, 732.

8. Barnes T.D. 2012. Review of Riot in Alexandria: Tradition and Group Dynamics in Late Antique Pagan and Christian Communities. The Transformation of the Classical Heritage, 46. The Catholic Historical Review. 98: 86-87.

9. Dzielska M. 1996. Hypatia of Alexandria. Cambridge, MA, London, 176.

10. Haas C. 1997. Alexandria in Late Antiquity: topography and social conflict. Baltimore; London, Johns Hopkins University press, 494.

11. Haas C. 2010. Alexandria Lost? Cleopatra and the End of the Hellenistic World. Franklin Institute and the University of Pennsylvania Museum of Archaeology and Anthropology. Philadelphia. URL: https://villanova.academia.edu/ChristopherHaas (дата обращения: 01.04.2020) (access date: 18.04.2020).

12. Hahn J. 2008. The Conversion of the Cult Statues. The Destruction of the Serapeion 392 A. D. From Temple to Church. Religions in the Graeco-Roman World, 161. Leiden, 335-366.

13. Kristensen T. 2009. Religious Conflict in Late Antique Alexandria: Christian Responses to «Pagan» Statues in the Fourth and Fifth Centuries CE. Alexandria. A Cultural and Religious Melting Pot. G. Hinge and J.A. Krasilnikoff (eds.). Aarhus, Aarhus University Press, 158-173.

14. Lacombrade C. 1994. Hypatia. Reallexikon für Antike und Christentum. Band 16. [Hypatia. Real Encyclopedia for Antiquity and Christianity. Volume 16]. Stuttgart, 956-967 (in German).

15. Łukaszewicz A. 2013. Lecture Halls at Kom el-Dikka in Alexandria. Divine men and women in the history and society of late Hellenism. Cracow, 101-112.

16. McDonald W. 2009. Alexandria in Late Antiquity: Topography and Social Conflict. By Christopher Haas. Baltimore: The Johns Hopkins University Press, 1997. 494 p. Church History: Studies in Christianity and Culture, 67(1). Cambridge: Cambridge University Press: 116-117.

16. McKenzie J. 2007. The Architecture of Alexandria and Egypt 300 B. C. to A. D. 700. New Haven; London, 460.

17. McKenzie J.S., Gibson S., Reyes A.T. 2004. Reconstructing the Serapeum in Alexandria from the Archaeological Evidence. The Journal of Roman Studies. Vol. 94: 73-121.

18. Ronchey S. 2001. Hypatia the Intellectual. Au. Fraschetti (eds.). Roman Women. Chicago; London, 160-189, 227-235.

19. Watts E.J. 2006. City and School in Late Antique Athens and Alexandria. The Transformation of the Classical Heritage 41. Berkeley; Los Angeles, University of California Press, 302.

20. Watts E.J. 2010. Riot in Alexandria: Tradition and Group Dynamics in Late Antique Pagan and Christian Communities. Berkeley, University of California Press, 290.

21. Watts E.J. 2017. Hypatia: The Life and Legend of an Ancient Philosopher. New York, Oxford University Press, 224.

\section{ИНФОРМАЦИЯ ОБ АВТОРЕ}

Руднева Мария Александровна, ассистент
кафедры всеобщей истории историко-
филологического факультета Педагогического
института Белгородского государственного
национального исследовательского университета,
г. Белгород, Россия

\section{INFORMATION ABOUT THE AUTHOR}

Maria A. Rudneva, assistant of the Department of General History, Institute of Pedagogy, Faculty of History and Philology, Belgorod National Research University, Belgorod, Russia 